\title{
Amino Acid Transport Systems in Animal Cells: Interrelations and Energization
}

\author{
Halvor N. Christensen \\ Department of Biological Chemistry, The University of Michigan, Ann Arbor, \\ Michigan 48109
}

\begin{abstract}
After summarizing the discrimination of the several transport systems for neutral amino acids in the cell of the higher animal, I discuss here the ways in which 2 dissimilar transport systems interact, so that one tends to run forward for net entry and the other backwards for net exodus. An evaluation of the proposals for energization shows that uphill transport continues when neither alkali-ion gradients nor ATP levels are favorable. Evidence is presented that under these conditions a major contribution is made by another mode of energization, which may depend on the fueling of an oxidoreductase in the plasma membrane. This fueling may involve the export by the mitochondrion of the reducing equivalents of NADH by one of the known shuttles, e.g., the malate-aspartate shuttle. After depletion of the energy reserves in the Ehrlich cell by treating it with dinitrophenol plus iodoacetate concentrative uptake of test amino acids is restored by pyruvate, but in poor correlation with the restoration of alkali-ion gradients and ATP levels. This restoration by pyruvate but not by glucose is highly sensitive to rotenone. A combination of phenazine methosulfate and ascorbate will also produce transport restoration, before either the alkali-ion gradients or ATP levels have begun to rise. The restoration of transport applies to a model amino acid entering by the $\mathrm{Na}^{+}$-independent system, as well as to one entering by the principal $\mathrm{Na}^{+}$-dependent system, restoration being blocked by ouabain, despite the weak effect of ouabain on the alkali-ion gradients in the Ehrlich cell. Quinacrine terminates very quickly the uptake of model amino acids, before the alkali-ion gradients have begun to fall and before the ATP level has been halved. Quinacrine is also effective in blocking restoration of uphill transport by either pyruvate or the phenazine reagent. Preliminary results show that vesicles prepared from the plasma membrane of the Ehrlich cell quickly reduce cytochrome $\mathrm{c}$ or ferricyanide in the presence of NADH, and that the distribution of a test amino acid between the vesicle and its environment is influenced by NADH, quinacrine, and an uncoupling agent in ways consistent with the above proposal, assuming that a majority of the vesicles are everted.
\end{abstract}

Key words: amino acid transport in animal cells, energization of transport systems, discrimination of transport systems, reverse operation of transport systems, Ehrlich cell, NADH dehydrogenase, alkali-ion gradients, phenazine methosulfate, ouabain

\section{TRANSPORT SYSTEMS AND THEIR INTERACTION}

The transport systems for neutral amino acids in the Ehrlich cell are taken to be approximately representative of those of the cells of the higher animal in general, with more and more evidence supporting that interpretation. Most conspicuous are a broad-

Received March 13, 1977; accepted April 3, 1977

(C) 1977 Alan R. Liss, Inc., 150 Fifth Avenue, New York, NY 10011 
range $\mathrm{Na}^{+}$-dependent system called $\mathrm{A}$ and a broad-range $\mathrm{Na}^{+}$-independent system called $\mathrm{L}(1)$. Another $\mathrm{Na}^{+}$-dependent system almost completely specific to glycine is not seen in the Ehrlich cell but has been described for nucleated and reticulated red blood cells, and may occur in a variant form with broader specificity in the intestine and kidney (Summaries, Refs. 2, 3). A third $\mathrm{Na}^{+}$-dependent system called ASC has an intermediate range of specificity embracing 3-to 5-carbon straight-chain amino acids and their hydroxy and sulfhydryl derivatives, also asparagine and glutamine, and the prolines. Its differences from System A leave no doubt of the independence of the 2: System ASC is less sensitive to $\mathrm{H}^{+}$and will not accept $\mathrm{Li}^{+}$as a substitute for $\mathrm{Na}^{+}$. The receptor site of System ASC binds the alkali ion at a closely specified point in juxtaposition to the hydroxyl group of ordinary (trans) 4-hydroxyproline (4), whereas System A binds $\mathrm{Na}^{+}$or $\mathrm{Li}^{+}$at a different, less precisely localized point rather nearer the $\beta$-carbon atom of the bound amino acid substrate (5). The ASC system is conspicuous in immature and nucleated red cells (6-8), leukemia cells (9), and lymphocytes (10); it participates in placental transport (11), and in general it appears to be ubiquitous.

The relation between Systems $A$ and $\mathrm{L}$ is the most interesting one, because essentially all the neutral amino acids are to some degree transported by both of these systems, although in different proportions. Because System A characteristically is strongly concentrative, and System L more weakly so, it can be shown that steady states are set up in which net uptake for various amino acids takes place by System A, and net exodus by System L (12). Amino acids with weak reactivity with System A and much stronger affinity for System $\mathrm{L}$ will therefore maintain only moderate gradients across the membrane, whereas those with the opposite pattern of preference will maintain rather high cellular levels relative to the extracellular fluid. The comparison is complicated somewhat, however, by effects of amino acid structure on the intensity of accumulation by System L.

My comments may be running contrary to an assumption about System $L$ that has gained unfortunate currency, namely that it produces exchange but not net uptake. This idea is easily refuted by experiments with model substrates specific to System L, using rather high concentrations to minimize the contribution of exchange (13). Net uptake and net exodus of phenylalanine by it also can be shown (14). I do not mean by this caveat, however, to question the importance of the heteroexchange activity of System L.

A specialization of one transport system in net uptake and another (by running backward) in net exodus of the same substrate seems highly useful in establishing the transport asymmetry of epithelial cells from one pole to the other, so that transcellular migration of nutrients can be produced without threatening the nutrition of the epithelial cell as in the small intestine, for example (15). But in nonepithelial cells, this specialization may also be advantageous in enhancing the regulatability of transport. If the energy sources of Systems A and L are distinct, as most evidence suggests, the duality of transport allows us to generalize the Mitchell hypothesis to include amino acid transport across the plasma membrane. The 2 energizing reactions can be coupled via the 2 transports.

\section{ENERGIZATION}

The more steeply uphill System $A$ in the cells of the higher animal can be driven by linked, down-gradient flows of the alkali ions, particularly the inward flow of $\mathrm{Na}^{+}(16-$ 18). This source of energy can account to a large extent, but not completely $(19,20)$ for the uphill transport of test amino acids when the cellular ATP is largely depleted. The energy calculated to be thus made available might perhaps become sufficient if hypotheti- 
cal increases in the transmembrane potential could be taken into account $(21,22)$. We have observed, however, conditions under which steeply uphill, $\mathrm{Na}^{+}$-dependent uptake of 2-aminoisobutyric acid (AIB) or its $\mathrm{N}$-methyl derivative (MeAIB) continues with little if any associated uptake of $\mathrm{Na}^{+}(13)$. Unless an ion actually moves in cotransport with the neutral amino acid, the value of the transmembrane potential appears to contribute nothing to an explanation. Hence the alkali-ion gradient hypothesis remains inadequate to explain $\mathrm{Na}^{+}$-dependent amino acid uptake.

Furthermore, respiratory poisons may largely fail to stop the uphill entry of the amino acids, whether $\mathrm{Na}^{+}$-dependent or $\mathrm{Na}^{+}$-independent. Eddy observed distinctly stronger accumulation of glycine for a given alkali gradient when respiratory metabolism took place than when it was prevented (19). Schafer and Williams have particularly emphasized the failure of the concentrative uptake of AIB to be eliminated when the ATP of the Ehrlich cell is sharply lowered by respiratory poisons, even when the electrochemical gradient of $\mathrm{Na}^{+}$is unfavorable (23). We find that after ATP depletion by simultaneous treatment of this cell with 2,4-dinitrophenol $(0.1 \mathrm{mM})$ and iodoacetate $(1 \mathrm{mM})$, the concentrative uptake of various amino acids is restored by supplying $10 \mathrm{mM}$ pyruvate before either the ATP level or the alkali-ion gradients are restored. Sensitivity of this effect to inhibition by rotenone suggests a mainly mitochondrial origin for the energy under these conditions (24). We raise the question, does the energy flow from the mitochondrion in a form other than ATP?

In the bacterial cell, electron transport and oxidative phosphorylation occur in the plasma membrane. Furthermore, large gradients of $\mathrm{H}^{+}$and of the electrical potential can be maintained across the plasma membrane, and nutrient molecules can be concentrated by their electrophoretic cotransport with $\mathrm{H}^{+}$made possible by these gradients. In the ascites tumor cell, in contrast, as in many other animal cells, the $\mathrm{pH}$ gradient and the transmembrane potential gradients tend to be quite small. Do the plasma membranes of animal cells differ from bacterial cells in not using proton gradients at all to intermediate between metabolic energy release and nutrient transport? Is amino acid transport energized on totally different principles in the animal cell? We have proposed that the mediating $\mathrm{H}^{+}$ gradients in the animal cell may be generated in and largely restricted to the membrane interior $(13,25,26)$. The present question is, however, a different one; not how the energy transduction occurs, but in what form is the energy brought to the membrane.

\section{ATP BREAKDOWN AND ENERGIZATION OF AMINO ACID TRANSPORT}

The conventional assumption has been that the flow of ATP to the membrane may serve to the extent that preexisting gradients, e.g., of the alkali ions, fall short. An amino acid stimulation of the $\mathrm{Na}^{+}$- and $\mathrm{K}^{+}$-dependent ATPase activity associated with the plasma membrane has been reported by Forte et al. (27). This activity applied, however, to both $\mathrm{D}$ and $\mathrm{L}$ isomers, and is shared with unnatural chelating agents. We have observed a stimulation of $\mathrm{Mg}^{2+}$-dependent ATPase activity in a preparation from the plasma membrane of the Ehrlich cell, in the absence of both $\mathrm{Na}^{+}$and $\mathrm{K}^{+}$and in the presence of ouabain (28). These properties might well correspond to $\mathrm{Na}^{+}$-independent System $\mathrm{L}$ which the $\mathrm{Na}^{+}$ gradient apparently does not energize at all. The stimulating amino acids inappropriately include L-ornithine (not D-ornithine), however; furthermore the norbornane amino acid is not stimulatory, even though it is a model substrate for System L; nor does it block the stimulatory effect of L-ornithine. We conclude that either ATP does not directly energize System L, or that we have not yet detected the ATPase corresponding to that system, or 
else perhaps that the ATPase activity has undergone alteration of its specificity during separation of the membrane fraction.

\section{AN OXIDOREDUCTASE SYSTEM ENERGIZING TRANSPORT IN THE PLASMA MEMBRANE?}

The question which now presents itself is, does the plasma membrane of the animal cell unexpectedly retain a redox system which allows it to energize transport? Do reducing equivalents flow from the mitochondrion to such a system? Although dehydrogenase activity for NADH has been detected in the plasma membrane of various cells, including nonnucleated red blood cells (29), hepatocytes, and adipocytes (30-32), these observations have been mainly incidental to the study of marker enzymes and until recently $(31,32)$ attracted little interest. It has occurred to us that NADH might reach the dehydrogenase of the plasma membrane by the transfer of its reducing equivalents from the plasma membrane via one of the shunts.

For example, the malate-aspartate shunt might serve, although the direction of that particular shunt has been seen as favoring movement of reducing equivalents in to the mitochondrion. Participation by that shunt could explain some earlier findings, as follows: Because transamination on both sides of the mitochondrial membrane is obligatory, a deficiency of vitamin $B_{6}$ might interfere with the maintenance of gradients of AIB by liver and muscle of the rat, with respect to the blood plasma (33), and vitamin $B_{6}$ analogs might interfere with intestinal amino acid transport, as has been repeatedly reported (34-36). Observation of these effects was at one time held to support an older hypothesis that the aldehyde group of pyridoxal phosphate might serve to take hold of the amino acid for transport. Other shuttles, described or undescribed, should also be considered.

\section{HORMONAL SENSITIVITY OF PLASMA MEMBRANE NADH DEHYDROGENASE}

The observation that NADH stimulates the adenylcyclase activity of plasma membranes of the hepatocyte and adipocyte (30) led to a search for the membrane-borne NADH sensor, with the result that responsive NADH dehydrogenase activity was discovered. Crane and Löw have recently reported that the NADH dehydrogenase of these 2 cells is characteristically sensitive to quinacrine (atebrin), azide, and triiodothyronine (31). The activity of the adipocyte membrane is stimulated by ACTH or glucagon, that of the liver cell by glucagon, at just the concentrations at which these hormones stimulate the adenylcyclase activity (32). Löw and Crane consider that the membrane NADH dehydrogenase has a monitoring function, i.e., in serving to regulate membrane activities to correspond to the metabolic state of the cell. Our present proposal adds the idea that this system may also serve to drive transport of amino acids and possibly other substances, as a significant biological alternative and complement to energization by cotransport with $\mathrm{Na}^{+}$and by ATP breakdown.

\section{PRELIMINARY FINDINGS}

We have now found informative a comparison between the rate of restoration of the following parameters after $30 \mathrm{~min}$ of depletion of energy reserves of the Ehrlich cell by $0.1 \mathrm{mM}$ dinitrophenol plus $1 \mathrm{mM}$ iodoacetate, or by $100 \mu \mathrm{g}$ of rotenone per liter: 1) Concentrative uptake of model amino acids; 2) Cellular ATP level; 3) Gradients of $\mathrm{Na}^{+}$and $\mathrm{K}^{+}$across the membrane. When a HEPES-buffered Krebs-Ringer medium containing $10 \mathrm{mM}$ pyruvate is substituted for the poisoning solution, the uptake of $\left[{ }^{14} \mathrm{C}\right] \mathrm{MeAIB}$ is restored in 3 min, during which time the ATP level rises, although the alkali-ion gradient 
(whether expressed as $\left(\left[\mathrm{Na}^{+}\right]_{\text {out }} \times\left[\mathrm{K}^{+}\right]_{\text {in }}\right) /\left(\left[\mathrm{Na}^{+}\right]_{\text {in }} \times\left[\mathrm{K}^{+}\right]_{\text {out }}\right)$ or as $\left.\left[\mathrm{Na}^{+}\right]_{\text {out }} /\left[\mathrm{Na}^{+}\right]_{\text {in }}\right)$ remains below $50 \%$ of normal. This early restoration of Me AIB transport by pyruvate is highly sensitive to rotenone, whereas that by glucose is not, a result which leads us provisionally to assign the restorative effect of pyruvate to mitochondrial oxidation.

\section{ARTIFICIAL HYDROGEN DONOR}

We have been able to replace pyruvate with the combination $0.1 \mathrm{mM}$ phenazine methosulfate plus $20 \mathrm{mM}$ sodium ascorbate for restoring MeAIB transport. This restorative effect differs from that of pyruvate, however, in that it is insensitive to rotenone inhibition. Figure 1 in our recent report (37) compares these restorative effects on (dinitrophenol + iodoacetate)-treated cells (left-hand section) and on rotenone-treated cells (right-hand section). Note that restoration of the MeAIB gradient had already progressed in the first min, and was already half complete in 4 or $5 \mathrm{~min}$, whereas the restoration of the ATP level and of the alkali-ion gradients had not yet begun. Transport restoration by pyruvate was not obtained in the right-hand section of the cited figure, where rotenone had been used as the metabolic poison. Figure 2 in the same paper showed that restoration of the fully $\mathrm{Na}^{+}$-independent uptake of the norbornane amino acid by phenazine-ascorbate was quite parallel. The amino acid gradients in this case typically continued to decline for $15 \mathrm{~min}$ after the dinitrophenol-iodoacetate had been removed, before application of the restorative reducing agent.

Figure 1 of the present paper shows a similar triplet of parallel experiments, in all of which, however, a 15-min delay was introduced after the dinitrophenol-iodoacetate or rotenone treatment before adding the phenazine-ascorbate. This figure also shows that restoration of amino acid gradients proceeds without rise in the severely depressed ATP levels or alkali-ion gradients. We argue that ATP of mitochondrial origin should pass through the cytoplasmic pool, to increase the cellular content. ATP of glycolytic origin might instead be introduced into a relatively small membrane-associated pool, as has been proposed for the transfer of ATP in the human red blood cell to the $\left(\mathrm{Na}^{+}+\mathrm{K}^{+}\right)$-ATPase $(38,39)$. Such a compartmentation seems unlikely, however, for ATP exported by the mitochondrion. Note that the restoration occurred under the same conditions for the $\mathrm{Na}^{+}$-independent uptake of the norbornane amino acid and the fully $\mathrm{Na}^{+}$-dependent uptake of MeAIB.

\section{ACTION OF OUABAIN ON PMS-ASCORBATE RESTORATION}

Figure 1 also shows that ouabain blocks the restorative effect of phenazine-ascorbate, not only for the $\mathrm{Na}^{+}$-dependent uptake of MeAIB, but apparently also for the $\mathrm{Na}^{+}$-independent uptake of the norbornane amino acid (Fig. 1). This effect is all the more remarkable because in this cell ouabain acts only sluggishly to decrease the alkali-ion gradients; also because we lack any obvious basis for blockage by ouabain of $\mathrm{Na}^{+}$-independent amino acid uptake. Perhaps you will suppose I have been wrong to stress in my first section the importance of discriminating among the transport systems, because the test of Fig. 1 seems to indicate a common basis of energization of 2 of them at least under selected conditions. This strong effect of ouabain, seen when the alkali-ion gradients are already unfavorable, and even for a model amino acid whose concentrative uptake is $\mathrm{Na}^{+}$-independent, suggests however, that we do not yet fully understand the full action of ouabain on membrane energetics. Kimmich has suggested that this agent acts on an ATPase serving for both the $\mathrm{Na}^{+}$-dependent transport of an organic metabolite and for the transport of the alkali ions (40). This proposal still does not seem broad enough to cover the present effect. A close 

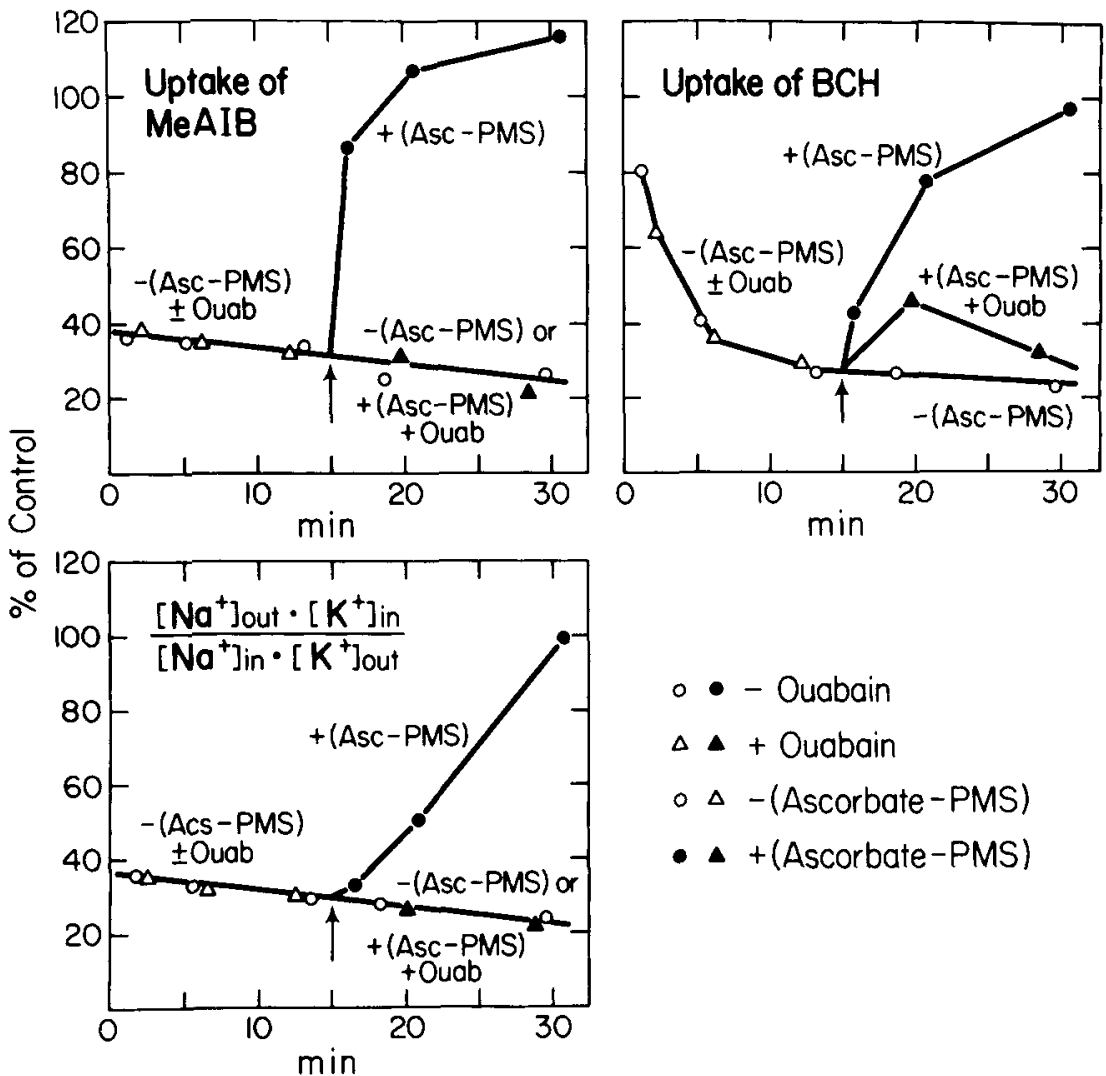

- - Ouabain

$\Delta \Delta+$ Ouabain

$0-$ (Ascorbate-PMS)

- $\Delta+($ Ascorbate-PMS)

Fig. 1. Time course of restoration by phenazine methosulfate $(0.1 \mathrm{mM})$ plus sodium ascorbate (20 mM) (ASC-PMS) of the 30-sec uptake of MeAlB (upper left) and of 2-aminonorbornane-2-carboxylic acid (upper right). Comparison with restoration of the alkali-ion gradients (lower left) $\left(\left[\mathrm{Na}^{+}\right]_{\text {out }} \cdot\left[\mathrm{K}^{+}\right]_{\text {in }}\right) /\left(\left[\mathrm{Na}^{+}\right]_{\text {in }} \cdot\left[\mathrm{K}^{+}\right]_{\text {out }}\right)$. The Ehrlich cells had been treated for the $30 \mathrm{~min}$ preceding the interval shown here with a $0.1 \mathrm{mM}$ dinitrophenol and $1 \mathrm{mM}$ iodoacetate, but these agents were absent from the medium for $15 \mathrm{~min}$ before the phenazine-ascorbate-reagent was added at the point indicated by the arrows. The $\left[{ }^{14} \mathrm{C}\right]$ amino acids were set at $20 \mu \mathrm{M}$. Note that the rate of amino acid accumulation in to the cell responds immediately, whereas the alkali-ion gradient responds sluggishly. As shown on Fig. 1 of reference (37), the cellular ATP levels in the meantime do not recover perceptibly in the presence of the phenazine-ascorbate reagent. Note that the presence of ouabain at $2 \mathrm{mM}$ largely prevents the recovery of amino acid uptake, even where it is $\mathrm{Na}^{+}$-independent.

interaction among the modes of membrane energization is indicated also by the continued influence of the transmembrane potential on amino acid uptake by cells treated with dinitrophenol and iodoacetate: The presence of valinomycin or thiocyanate produced a $40-60 \%$ stimulation of MeAIB uptake without any increase in the ATP concentration and despite the low alkali-ion gradients.

\section{QUINACRINE}

Crane and Löw considered characteristic the quinacrine sensitivity of the NADH dehydrogenase of the plasma membrane of the hepatocyte and the adipocyte (31). We 
find that quinacrine at 2-3 $\mathrm{mM}$ terminates the uptake of MeAIB by the Ehrlich cell more quickly and more completely than any other inhibitor heretofore tested. After $30 \mathrm{sec}$ of contact, the uptake of MeAIB measured during that $30 \mathrm{sec}$ was decreased by $75-85 \%$, before the cellular ATP level had been halved and before the alkali-ion gradients had even begun to fall. We reason that in this short time interval quinacrine is likely to have inhibited mainly dehydrogenase action in the plasma membrane, and rather less than in the mitochondrion. A further delay may be expected in the communication of the consequences of mitochondrial inhibition to the plasma membrane. To strengthen this argument, quinacrine should be tested on mitochondria-free plasma membrane vesicles. Quinacrine is as effective as ouabain in eliminating the restoration by pyruvate or by phenazine of MeAIB transport in the energetically depleted cells (see Fig. 1).

\section{PRE LIMINARY EXPERIMENTS WITH VESICLES PREPARED FROM THE PLASMA MEMBRANE OF THE EHRLICH CELL (28)}

These vesicles were incubated for $30 \mathrm{sec}$ in Krebs-Ringer phosphate medium containing $0.2 \mathrm{mM}\left[{ }^{14} \mathrm{C}\right] \mathrm{MeAIB}$, at $\mathrm{pH} 7.4$ and $37^{\circ} \mathrm{C}$. The vesicles were then separated by filtration on a glass-fiber filter, and the radioactivity of the vesicles referred to the protein content. The following tabulation compares the ${ }^{14} \mathrm{C}$ taken up into the vesicles under these conditions with the amount taken up when the indicated agents were present during the 30 sec:

$\begin{array}{ll}\text { Control } & 0.148 \\ 0.4 \mathrm{mM} \text { quinacrine } & 0.231 \\ 0.33 \mathrm{ng} \mathrm{FCCP} / \mathrm{ml} & 0.224 \\ 1.8 \mathrm{mM} \mathrm{NADH} & 0.071\end{array}$

These effects correspond to the acceptance of NADH by the plasma membrane to produce transport, if we suppose that more of our vesicles were everted than right-side-out. Extrusion of the entering MeAIB in that case would appear to have been inhibited to the extent of 51 and $56 \%$, respectively, by quinacrine and by trifluoromethoxy-carbonylcyanide phenylhydrazone.

\section{DISCUSSION}

On the basis of the above results we propose provisionally that amino acid transport by the Ehrlich cell can be energized either by the alkali-ion gradients, by cellular ATP, or by reducing equivalents that may reach the plasma membrane from the mitochondrion by way of an unidentified shuttle. The natural electron acceptor which presumably accounts for the effectiveness of the reducing equivalents remains unidentified. In the case of the heretofore studied NADH dehydrogenase of plasma membranes, various artificial acceptors have been effective, including ferricyanide, glyoxylate, and dichlorophenol indophenol.

The malate-asparate shunt is known to be operative in the Ehrlich cell (41). Its contribution should be recognizable by a sensitivity to inhibition by the pyridoxal phosphate binding reagent, aminooxylate. A preliminary test failed to show inhibition of phenazineascorbate restoration of MeAIB uptake by the Ehrlich cell by this reagent at $0.5 \mathrm{mM}$. 
The conditions of our experiments may be such as to maximize the proposed contribution of reducing equivalents from the mitochondrion to transport. It is known that the malate-asparate shunt tends to transfer reducing equivalents inwardly when ATP levels are high, and outwardly when ATP production is restricted (42). At the same time it does not appear to be fully proved that the breakdown of ATP per se drives amino acid transport; hence it would be premature to ascribe limits to the contribution of the mitochondrion by other of its products than ATP.

The effect of ouabain to block transport restoration may well have an origin other than its diminution of the alkali-ion gradients. It is known that external $\mathrm{K}^{+}$at $0-2 \mathrm{mM}$ concentrations regulates oxygen consumption by this cell (43). These are $\mathrm{K}^{+}$levels that also govern alkali-ion transport by the plasma membrane; furthermore these effects of $\mathrm{K}^{+}$ can be blocked by ouabain (Ref. 43 and references therein). The present sensitivity of $\mathrm{Na}^{+}$-independent transport to ouabain suggests that amino acid transport is energized in part by a component of respiratory metabolism controlled by $\mathrm{K}^{+}$-binding sites at the external surface of the cell.

Finally, we should note that an ability of the phenazine-ascorbate mixture or of NADH to energize transport by the plasma membrane has quite different implications than it does for vesicles of E. coli (44) or B. subtilis (45). In these bacterial organisms the plasma membrane is known to contain the respiratory chain, and energization of transport appears to occur through reactions within that chain. In cells of the higher animal, in contrast, the respiratory chain is considered to have taken its place in the inner mitochondrial membrane.

\section{ACKNOWLEDGMENTS}

I acknowledge research support from the Institute of Child Health and Human Development, Grant HD01233, National Institutes of Health, U.S. Public Health Service, and the important collaboration of the coauthors named in the list of references.

\section{REFERENCES}

1. Oxender DL, Christensen HN: J Biol Chem 238:3686, 1963.

2. Christensen HN: Adv Enzymol 32:1, 1969.

3. Christensen HN: Curr Top Membr Transp 6:227, 1975.

4. Thomas, EL, Christensen HN: Biochem Biophys Res Commun 40:277, 1970.

5. Christensen HN, Handlogten ME: J Membr Biol, in press.

6. Vidaver G: Biochemistry 3:662, 1964.

7. Thomas EL, Christensen HN: J Biol Chem 246:1682, 1971.

8. Eavenson E, Christensen HN: J Biol Chem 242:5386, 1967.

9. Wise WC: J Cell Physiol 87:199, 1976.

10. Wise WC: Fed Proc Fed Am Soc Exp Biol 35:605, 1976.

11. Enders RH, Judd RM, Donohue TM, Smith CH: Am J Physiol 230:706, 1976.

12. Christensen HN: In Levi G, Battistin L, Lajtha A (eds): "Transport Phenomena in The Nervous System." New York: Plenum Press, 1973, p 3.

13. Christensen HN, deCespedes C, Handlogten ME, Ronquist G: Biochim Biophys Acta 300:487, 1973.

14. Christensen HN, Handlogten ME: J Biol Chem 243:5428, 1968.

15. Christensen HN: In Proc 6th Int Cong Nephrol, Florence. Basel: Karger, 1975, p 134.

16. Christensen HN, Riggs TR: J Biol Chem 194:57, 1952.

17. Riggs TR, Walker LM, Christensen HN: J Biol Chem 233:1479, 1958.

18. Schultz SG, Curran PF: Physiol Rev 50:637, 1970.

19. Eddy AA: Biochem J 108:489, 1968. 
20. Schafer JA, Heinz E: Biochem Biophys Acta 249:15, 1971.

21. Gibb LE, Eddy AA: Biochem J 129:979, 1972.

22. Heinz E, Geck P, Pietrzyk C, Pfeiffer B: In Semenza G, Carafoli E (eds): "Proc of FEBS Symp 42, Biochemistry of Membrane Transport." Berlin: Springer, 1977, p 236.

23. Schafer JA, Williams AE: In Silbernagel G, Lang F, Greger R (eds): "Amino Acid Transport and Uric Acid Transport." Stuttgart: Georg Thieme, 1976, p 20.

24. Christensen HN, Garcia-Sancho J, Sanchez A: J Supramol Struct, Suppl 1:154, 1977.

25. Christensen HN, deCespedes C, Handlogten ME, Ronquist G: Ann NY Acad Sci 227:335, 1974.

26. Christensen HN, Handlogten ME: Proc Natl Acad Sci USA 72:23, 1975.

27. Forte JG, Forte TM, Heinz E: Biochim Biophys Acta 298:827, 1973.

28. Im WB, Christensen HN, Sportés B: Biochim Biophys Acta 436:424, 1976.

29. Samudio I, Canessa M: Biochim Biophys Acta 120:165, 1966.

30. Löw H, Werner S: FEBS Lett 65:96, 1976.

31. Crane FL, Löw H: FEBS Lett 68:153, 1976.

32. Löw H, Crane FL: FEBS Lett 68:157, 1976.

33. Riggs TR, Walker LM: J Biol Chem 233:132, 1958.

34. Jacobs FA, Hillman RSL: J Biol Chem 232:445, 1958.

35. Akedo H, Sagawa T, Yoshikawa S, Suda M: J Biochem (Tokyo) 47:124, 1960.

36. Ueda K, Akedo H, Suda M: J Biochem (Tokyo) 48:584, 1960.

37. Garcia-Sancho J, Sanchez A, Handlog ten ME, Christensen HN: Proc Natl Acad Sci USA 73, vol $74, \mathrm{p} 1488$.

38. Parker JC, Hoffman JF: J Gen Physiol 50:893, 1967.

39. Proverbio F, Hoffman JF: Ann NY Acad Sci 242:459, 1974.

40. Kimmich GA: Biochemistry 9:3669, 1970.

41. Greenhouse WVV, Lehninger AL: Cancer Res 36:1392, 1976.

42. Bremer J, Davies EJ: Biochim Biophys Acta 376:387, 1975.

43. Levinson C, Hempling HG: Biochim Biophys Acta 135:307, 1967.

44. Konings WN, Barnes EM, Kaback HR: J Biol Chem 246:5857, 1971.

45. Hayakawa K, Veda T, Kasaka I, Fukui E: Biochem Biophys Res Commun 72:1548, 1976. 